\title{
ANÁLISE DE CONTO ESCRITO POR HANS CHRISTIAN ANDERSEN (1805-75): “O ISQUEIRO MÁGICO".
}

\author{
Rosana da Silva Santos Jurazeky, Ana Maria Martins da Costa Santos
}

Universidade Estadual Paulista/ Faculdade de Ciências e Tecnologia - UNESP - Presidente Prudente. E-mail: jurazekyrosana@yahoo.com.br

\section{RESUMO}

A pesquisa "Análise de contos escritos por Hans Christian Andersen (1805-75): 'O isqueiro mágico' e "A rainha da neve" pautou-se na concepção de linguagem entendida como um processo de interação humana e no ato de ler, como uma atividade complexa, envolvendo aspectos não somente gramaticais e semânticos, mas pragmáticos e dialógicos. Esta concepção teórica foi adotada por estar de acordo com os objetivos desta investigação: 1) Analisar a estrutura textual e temática dos contos de H. C. Andersen, observando os aspectos comuns relativos ao tema, assunto, mensagem; ao enredo; ao tempo, ao espaço e lugar; ao narrador e ao foco narrativo; às personagens; 2) Construir subsídios teóricos para definir critérios sobre a escolha de um livro ou de um conto de literatura infantil; 3) Apresentar a análise estrutural dos contos: " $O$ isqueiro mágico" e "A rainha da neve", de H. C. Andersen. O foco do estudo definiu-se em relação ao texto narrativo/clássico da literatura infantil. As atividades desenvolvidas foram de cunho bibliográfico, que acompanharam todo o processo de investigação. Após o levantamento e leitura dos contos, optou-se pelos seguintes títulos "O isqueiro mágico" e "A rainha da neve", selecionados a partir do conjunto da obra de H. C. Andersen. Por fim, o fato de a leitura se constituir em um dos grandes problemas vividos pela escola e pela sociedade como um todo, como àqueles relativos ao analfabetismo funcional, à não formação do leitor e não compreensão de textos literários, aspectos estes, que são demonstrados nos resultados obtidos pelos alunos na Provinha Brasil, Saresp e PISA, justificam uma pesquisa que venha a contribuir para a superação do status quo.

Palavras-chave: Hans Christian Andersen; Linguagem Dialógica; Leitura;Literatura infantil.

\section{INTRODUÇÃO}

Cosson (2006) aponta em seus estudos que a literatura infantil vem sendo considerada, em diferentes níveis e momentos do processo de aprendizagem, como um saber desnecessário. Para alguns segmentos sociais, a literatura é retrato da burguesia, de um tempo passado e, por esta razão, deveria ter sido abolida da escola. Já outros segmentos desconhecem a literatura e julgam que o esforço para conhecê-la é desproporcional se comparado a seus benefícios.

Diante deste cenário, o espaço da literatura na formação inicial e continuada de professores é posto em segundo plano. O próprio curso de graduação em Pedagogia da FCT/UNESP, por exemplo, oferecia a disciplina de literatura infantil como optativa; contudo, com uma reduzida carga horária. 
Em contrapartida alguns estudiosos defendem a inserção da literatura infantil na escola como um saber necessário à formação humana. Neste sentido, a atuação dos professores em sala de aula é considerada condição sine qua non para a construção do aluno leitor. Para Anne-Marie Chartier (2005, p. 89):

Caberá aos futuros professores orientar leituras. Por isso, fazê-los refletir sobre suas maneiras de ler, sobretudo no contexto da formação inicial, poderia ajudá-los a definir as estratégias e percursos de leitura mais adequados para o desenvolvimento de processos de formação de seus alunos.

Considero portanto que, tanto para o curso de formação inicial quanto para o de formação continuada de professores, a leitura é uma ferramenta de trabalho diferenciada em relação a outros profissionais, pois é um espaço de cultura pessoal que deve ser compartilhada e (re) construída diariamente.

Soares (1999, p. 43-44) enfatiza que para se formar um bom leitor de literatura é necessário realizar

A análise do gênero do texto, dos recursos de expressão e da recriação da realidade, das figuras autor-narrador, personagem, ponto de vista (no caso da narrativa), a interpretação de analogias, comparações, metáforas, identificação de recursos estilísticos, poéticos, enfim, o "estudo" daquilo que é textual e daquilo que é literário.

Compartilho com as reflexões propostas por Soares, entendendo ser necessária para uma adequada escolarização da literatura infantil e, em particular, para que o professor utilize os contos de H. C. Andersen na escola, uma construção e consolidação teórica dos aspectos relativos à estrutura da narrativa.

\section{OBJETIVOS}

1) Analisar a estrutura textual e temática dos contos de H. C. Andersen, observando os aspectos comuns relativos ao tema, assunto, mensagem; ao enredo; ao tempo, ao espaço e lugar; ao narrador e ao foco narrativo; as personagens;

2) Construir subsídios teóricos para definir critérios sobre a escolha de um livro ou de um conto de literatura infantil;

3) Apresentar a análise estrutural dos contos: "O isqueiro mágico" e "A rainha da neve", de H. C. Andersen. 


\section{METODOLOGIA}

Para desenvolver uma pesquisa com estas características encontrei em André (1995, p. 17) subsídios conceituais que permitissem definir o meu caminhar nesta investigação. Segundo a autora, a pesquisa de abordagem qualitativa é

(...) naturalística ou naturalista porque se contrapõe ao esquema quantitativista de pesquisa (que divide a realidade em unidades passíveis de mensuração, estudando-as isoladamente, defendendo uma visão holística dos fenômenos, isto é, que leve em conta os componentes de uma situação em suas interações e influências recíprocas).

Partindo do pressuposto de que a abordagem qualitativa concebe o sujeito e o mundo real em um processo vivo, indissociável e interdependente, justifico a opção por este tipo de abordagem, cuja organização e pressupostos ajudarão a responder aos objetivos desta investigação.

Uma das formas de se fazer pesquisa na abordagem qualitativa é a pesquisa bibliográfica, desenvolvida a partir de material já elaborado constituído principalmente de livros e artigos científicos.

No intuito de obter dados para esta investigação recorri a fontes de informação, como versões dos contos de H. C. Andersen de diferentes editoras (Companhia da Letrinhas, Ática, Moderna e outras de grande circulação). A fim de cumprir os objetivos propostas nesta investigação utilizo:

- Sobre vida e obra de Hans Christian Andersen: Jurazeky (2007), Ana Maria Martins da Costa Santos (1999), J. Myilus (1997), Silva Duarte (1995).

- Sobre estrutura da narrativa: Cândida V. Gancho (2004), João Batista Cardoso (2001), Heidi Strecker Gomes (1991) e Benedito Nunes (1988).

- Os contos: Guttorm Hanssen (1981).

- Sobre os contos de H.C. Andersen e a escola: Ana Maria Martins da Costa Santos e Renata Junqueira de Souza (2011).

A investigação organizou-se obedecendo às seguintes etapas:

- Levantamento no banco de teses e dissertações da USP, UNICAMP, UNESP, INEPE, FAPESP e outras universidades de diferentes estados brasileiros, com pesquisas voltadas sobre H. C. Andersen. E busca no Banco Internacional de Objetos Educacionais com software voltado para os contos de H. C. Andersen, buscando verificar a relevância e caráter inédito da pesquisa; 
- Levantamento e leitura de alguns dos 156 contos escritos por H. C. Andersen, que foram publicados no Brasil;

- Análise da estrutura dos contos propostos: "O isqueiro mágico" e "A rainha da neve";

- Registro processual da pesquisa e elaboração da tese;

- Divulgação da pesquisa e publicação dos resultados obtidos.

\section{DISCUSSÃO}

Hans Christian Andersen nasceu em dois de abril de 1805, em Odense, Dinamarca. O lugar de seu nascimento não é de conhecimento público. Alguns historiadores acreditam que ele tenha nascido na casa de Hans Jensensstraede, mas a casa de Munkemollestraede é onde viveu entre 1807 e 1819.

Filho de um sapateiro, Hans Andersen, e de uma lavadeira, Anne Marie Andersdatter. Ele nunca escondeu sua origem, pelo contrário, orgulhava-se dela, embora sua origem tenha sido um dos grandes entraves para ser aceito no ofício de escritor (DUARTE, 1995). Para alguns pesquisadores, sua origem humilde foi responsável pelo fortalecimento de seu realismo e de sua consciência social.

Em quatro de agosto de 1875 vem a falecer em casa de amigos, que cuidaram dele durante os últimos anos de sua vida.

Sua vida exerceu forte influência sobre sua obra: a existência é maravilhosa, é preciso sofrer para vencer, há forças boas que auxiliam os infelizes, porém virtuosos. Aspectos inerentes à sua personalidade e vida estão presentes e se manifestam de forma literária em seus contos, a exemplo de "As flores da pequena Ida", na qual um jovem estudante conta histórias para a menina Ida e estas histórias eram consideradas pela personagem o conselheiro como inadequadas para uma criança porque tratavam da morte.

A primeira publicação de contos escritas por H. C. Andersen para crianças data de 1835, intitulada "Contos de fadas para crianças" o livro contem as histórias: "O isqueiro", "Nicolau Grande e Nicolau Pequeno" e "A princesa e o grão de ervilha". Este fascículo foi criticado na época de sua publicação porque para algumas pessoas os textos eram inapropriados para crianças. A este respeito H. C. Andersen comentou que,

De tudo o que escrevi até hoje, nenhum trabalho produziu reações tão diferentes quanto os meus "Contos de Fadas para Crianças". Para uns poucos, cujo julgamento muito prezo, essas historietas infantis eram a 
melhor coisa que eu já havia publicado, enquanto que outros não lhes deram qualquer importância, chegando mesmo a aconselhar que eu desistisse de prosseguir nessa linha de trabalho. Essas diferentes opiniões, aliadas ao silêncio dos críticos profissionais, enfraqueceram meu desejo de retornar às incursões nesse gênero literário. Assim, um ano se passou, até que o terceiro fascículo se seguisse aos dois primeiros. (AMADO, 1996, p. 15).

Duarte (1995) apresenta três fases na obra de H. C. Andersen: nos primeiros dez anos não possui formato claro porque ora escreve peças teatrais ora contos; a partir de 1835, começa a escrever muitos contos, por exemplo: "O isqueiro mágico" em que H. C. Andersen rompe com o modelo tradicional e escreve um conto cujo protagonista é um anti-herói, característica que o autor traz antes do surgimento do Realismo e Modernismo; portanto, podemos afirmar que H. C. Andersen está à frente de seu tempo.

A segunda fase é marcada pelo conto trágico, como em "História da mãe", em que o autor apresenta uma narrativa próxima à realidade e com finais infelizes. Na "História da mãe", a personagem principal passa por um grande problema: a doença do filho que o leva à morte. É um conto que retrata o período de luta, aceitação e regeneração.

A terceira fase, a partir de 1851, mostra-se integrado à sua arte: “Cinco grãos de uma só vagem" representa o ápice do escritor, livre de modelos, liberto de seus medos e angústias. Esta fase representa um amadurecimento pessoal e artístico. O conto "Cinco grãos de uma vagem só" demonstra sutilmente como a vida deve ser encarada, que, dependendo do ponto de vista, da maneira que vivemos ela pode ser mais agradável e feliz.

\section{RESULTADOS PARCIAIS}

Pensando nas transformações que, geralmente, ocorrem em uma narrativa, deve-se observar o fato de que, não há uma estrutura fixa a ser seguida. Todavia tem-se uma estrutura e para compreendê-la é preciso saber identificar as personagens da história, seus papéis, ou seja, qual é e como é seu fazer transformador.

Toda narrativa se estrutura sobre cinco elementos essenciais, sem os quais não pode existir. Sem os acontecimentos não é possível contar uma história. Quem vive os acontecimentos são as personagens, em tempos e espaços determinados. Por fim, é necessária a presença de um narrador - elemento fundamental à narrativa - uma vez que ele narra/conta a história, fazendo a mediação entre esta e o ouvinte, leitor ou espectador. Tratarei, por esta razão, do enredo (o tema, o assunto e a mensagem das histórias), tempo, espaço e narrador, bem como de suas 
particularidades na constituição das narrativas de contos. Os contos analisados na pesquisa foram: "O isqueiro mágico" e "A rainha da neve", mas selecionei apenas o primeiro para a apresentação deste artigo.

O conto "O isqueiro mágico" trata de uma personagem que encontra um objeto mágico e realiza todos os seus desejos. Este é o tema principal do conto e é também o desejo de qualquer leitor, ou seja, ter um objeto mágico para resolver todos os seus problemas e conflitos; talvez por este motivo, este conto tenha se perpetuado ao longo de tantos anos.

No desenrolar da narrativa o tema vai sendo abordado por meio da apresentação de dois desejos comuns ao ser humano: a realização amorosa e financeira. A mensagem final, para o leitor, fecha esta ideia de que somente o dinheiro não é suficiente para sermos felizes, é preciso ter um grande e verdadeiro amor, que ele conquista casando-se com a princesa. Porém, ainda sim, eliminando os obstáculos que foram surgindo em sua vida. Primeiro a velha senhora, depois o rei, a rainha e a guarda. Somos levados a pensar que a trajetória do soldado é também solitária. Ele tem planos, desejos e tudo faz para conquistá-los. Os que estão à sua volta, não têm voz. São conduzidos por ele, como por exemplo, temos a princesa que é submissa e acata as vontades de seu pai e depois submete-se aos desejos do soldado, pois em nenhum fragmento conhecemos seus desejos, sua voz.

H. C. Andersen rompe com as marcas literárias de seu tempo (1805-1875), isto é, apresenta características do Realismo e Modernismo, descrevendo como protagonista um anti-herói, mau, trapaceiro, indolente.

O soldado mata a velha senhora, o rei, a rainha, os guardas e juízes do rei, toma a princesa e apresenta apenas três atos bons: dá dinheiro aos pobres, cumpre o combinado com o aprendiz de sapateiro e dá assento de honra aos cães. A riqueza e a união com a princesa são conquistados por um toque de mágica e não por merecimento, pois o soldado não faz o bem a ninguém, somente a ele próprio.

A grande contribuição de H. C. Andersen está em romper com os modelos tradicionais: do protagonista herói e do final feliz, ele demonstra neste conto que na vida há pessoas más e egoístas que podem não ser punidas e ter um final feliz à custa do sofrimento dos outros.

O enredo é linear, há uma introdução em que são apresentadas as personagens, o tempo e o espaço que se encerra com o dano, ou seja, o soldado mata a velha. No desenvolvimento da narrativa o soldado vive uma vida folgada, gastando todo o dinheiro, depois perde tudo e num toque de mágica (toque do isqueiro) conquista a fortuna e conhece uma linda princesa. $\mathrm{Na}$ 
conclusão o leitor perceberá o anticlímax quando a rainha usando de sua sagacidade amarra uma bolsinha com grãozinhos de sorgo nas costas da princesa que é levada pelos cães até a hospedaria; neste momento ocorre o conflito principal na narrativa, o soldado é descoberto e preso pelos soldados do rei.

Condenado a morrer na forca inicia-se um novo anticlímax quando o aprendiz de sapateiro ajuda o soldado levando o isqueiro para ele, culminando no clímax que é o acionamento do isqueiro pelo soldado já no alto do estrado onde seria enforcado.

O desfecho ocorre com os cães salvando o soldado. Aclamado rei pelo povo, uniu-se à princesa. Reconhecendo o serviço prestado pelos cães dá-lhes assento honroso à mesa festiva.

Partindo da analise da estrutura da narrativa o professor pode e deve utilizar adequadamente a leitura deste conto para incentivar a leitura de seus alunos.

\section{REFERÊNCIAS}

Amado, E. Histórias e Contos de Fadas. Belo Horizonte: Villa Rica, 1996, 2 vol.

ANDRÉ, M.E.D. Etnografia da prática escolar. Campinas: Papirus, 1995.

CARDOSO, João Batista. Teoria e prática de leitura, apreensão e produção de texto. Brasília: Edunb, 2001.

CHARTIER, Anne-Marie. Os futuros professores e a leitura. In: Galvão, A.M.O.; Batista, A.A.G. (orgs). Leitura: práticas, impressos, letramentos, Belo Horizonte: Autêntica, 2005, p. 89-98.

COSSON, Rildo. Letramento literário: teoria e prática. São Paulo: Contexto, 2006.

DUARTE, SILVA. Andersen e sua obra. Lisboa, Portugal: Livros Horizontes, 1995. GANCHO, Cândida Vilares. Como analisar narrativas. São Paulo: Ática, 2004.

GOMES, Heidi Strecker. Análise de texto: teoria e prática. São Paulo: Atual, 1991.

HANSSEN, Guttorm. Contos de Andersen. Rio de Janeiro: paz e Terra, 1981.

JURAZEKY, R. S. S. “O patinho feio" e “O rouxinol e o imperador da China”, de Hans Christian Andersen: a literatura infantil em uma 4a série do ensino fundamental em Presidente Prudente. Presidente Prudente: Universidade Estadual Paulista, 2007, Dissertação de mestrado.

MENIN, AM.C.S. O patinho feio de Hans Christian Andersen: o "abrasileiramento" de um conto para crianças. Assis: Universidade Estadual Paulista, 1999.

MYILUS, J. Hans Christian Andersen. Tradução Daniel S. Babenco. Real Ministerio de Relaciones Exteriores/Departamento de Información. Dinamarca: Flemming Axmark, 1997. 
Encontro de Ensino, Pesquisa e Extensão, Presidente Prudente, 21 a 24 de outubro, 2013

NUNES, Benedito. 0 tempo da narrativa. São Paulo: Ática, 1988

SANTOS, A. M. M. C.; SOUZA, R.J. Andersen e as estratégias de leitura: atividades práticas no cotidiano escolar. Campinas: Mercado de Letras, 2011.

SOARES, M. A escolarização da literatura infanto-juvenil. In: Martins, A.A.; Brandão, H. M. E. \& Machado, M. Z. V. Escolarização da leitura literária: o jogo do livro infantil e juvenil. Belo Horizonte: Autêntica, 1999, p. $17-48$. 